\title{
Boundary Spanning Among Community-Engaged Faculty: An Exploratory Study of Faculty Participating in Higher Education Community Engagement
}

\author{
Jennifer Purcell, Andrew Pearl, Trina Van Schyndel
}

\begin{abstract}
The purpose of this study was to explore faculty members' perceptions of their roles as boundary spanners, the expectations they have for professional competencies related to boundary spanning, and how these faculty members were prepared to perform successfully in their boundary spanning roles. In the context of higher education community engagement, boundary spanning refers to the work that is critical in overcoming the divide between the institution and the community (Weerts \& Sandmann, 2010). This study revealed boundary spanning faculty members' perceptions of their roles, competencies for effective community-engaged teaching and scholarship, and ways in which institutions may cultivate and support boundary spanning among current and future scholars and educators.
\end{abstract}

KeYWorDs boundary spanning, community engagement, faculty development, higher education

A renewed commitment to higher education's public and civic purpose continues to build momentum, as evidenced by the higher education community engagement movement (Sandmann \& Jones, 2019). In the context of the Carnegie Foundation for the Advancement of Teaching's elective classification, higher education community engagement (HECE) is defined as the "collaboration between institutions of higher education and their larger communities (local, regional/state, national, global) for the mutually beneficial exchange of knowledge and resources in a context of partnership and reciprocity" to enhance and strengthen the work of the institution (CUEI, n.d.). University-community partnerships provide the foundation for community engagement in higher education, and individual actors play a significant role in establishing and sustaining these partnerships. In these partnerships, these individuals, who we identify as boundary spanners, may be positioned as members of the university community or a member of the surrounding community. Regardless of their position, they play a vital role in supporting university-community partnerships and advancing institutional community engagement initiatives. Their efforts contribute to the institutionalization of community engagement, which encompasses the broad and substantive integration of community-engaged activities and their alignment with core commitments and a university's mission. 
Within the literature on community engagement in higher education, a breadth of articles and texts explore a subset of related topics, including the historical and philosophical foundations undergirding higher education's commitment to community engagement (Gavazzi \& Gee, 2018; Saltmarsh \& Hartley, 2011), best practices for university-community partnerships (see Campus Compact; Community-Campus Partnerships for Heath), approaches to communityengaged pedagogy (Welch \& Plaxton-Moore, 2019) strategies for effective community-engaged research (Berkey et al., 2018; Post et al., 2016), and institutional infrastructure, policies, leadership, and organization development specific to community engagement (Beere et al., 2011). Scholars of community engagement in higher education represent various disciplinary backgrounds; as such, their research examines higher education community engagement (HECE) from multiple positional and theoretical lenses. Likewise, research on community engagement encompasses exploration at the macro to the micro-level, ranging from industrywide commitments to institutional infrastructure and policy (see Welch, 2016), to faculty and staff development (see Dostilio, 2017), to student learning (see Jacoby, 2014), and myriad topics in between. Our research examines the role and contributions of community-engaged faculty members as boundary spanners who support HECE.

Through their curricular contributions, a core academic function of the university, faculty members who integrate community-engaged pedagogy and pursue community-engaged research are part of the essential bedrock through which comprehensive HECE commitments and activities are sustained. Therefore, proponents of HECE need to understand how these faculty are identified, empowered, cultivated, and rewarded. Fortunately, a growing body of research illuminates aspects of faculty support and development related to HECE. There is evidence of research informing practices further to enhance the impact of these faculty members' contributions. While the research to date equips scholars and practitioners with valuable insights and recommendations, each new study and publication reveals greater clarity on what we have yet to uncover. Research on community-engaged faculty is primed for continued inquiry. The current global political climate and societal context indicate a significant need for faculty who are adept at collaborative, applied research that addresses the pressing challenges of the 21st century. Specifically, research on boundary spanning faculty is needed to advance HECE further and, more holistically, to support their efforts to educate and prepare engaged citizens and address complex real-world problems through solutions-focused research.

\section{Background}

To better understand the role of boundary spanning faculty members, this exploratory study examines perceptions of the competencies required for this role among faculty who participate in HECE. Boundary spanning is an essential function for HECE, and faculty members who collaborate with community-based partners and members of the university community exhibit boundary spanning behaviours. Therefore, we posit that faculty engaged in HECE are inherently involved in boundary spanning to some degree. For this study, we identified a pool of exemplary community-engaged professors employed by large public research universities in the United States. The study recognizes influential boundary spanning faculty members 
as a core element of a comprehensive HECE leadership network. It builds upon Weerts and Sandmann's (2010) seminal work to advance how we cultivate and support community-engaged faculty. This inquiry is informed by research on HECE, including the institutionalization of community engagement; faculty development and support, including relevant literature from research on human resources and organization development; and public leadership, including higher education leadership and leadership specifically for HECE.

To provide context and situate this study among published research, we begin by introducing the historical literature on boundary spanning, including its origins in management research, to its more recent inclusion in public administration and public leadership literature. The review is not intended to be exhaustive of literature on the topic; instead, it seeks to introduce seminal articles and current research that informs this study, including boundary spanning competencies identified for public contexts. As an example of multidisciplinary research, this study is informed by relevant literature from three interdisciplinary fields: public leadership, higher education community engagement, and faculty-related professional and organizational development. In the decade since the Weerts and Sandmann (2010) article introduced the application of the boundary spanning framework within the context of HECE, multiple studies have explored a variety of aspects of boundary spanning related to community engagement, yet there is still much to uncover. Similarly, research on boundary spanning in other contexts and applications, such as a function of leadership and public networks, enhances our understanding of boundary spanning behaviour and roles and their potential in 21 st century life.

\section{Organizational Boundary Spanning}

The concept of organizational boundary spanning as a function of leadership first emerged in the literature on management in the 1970s before taking root among scholars of public administration and public leadership. The primary goal of organizational boundary spanning is to process and transmit information between organizations and represent the organization to external stakeholders (Aldrich \& Herker, 1977). Although boundary spanning work can be examined from both the individual and organizational levels (Friedman \& Podolny, 1992), this research specifically focuses on individual faculty members' work and the competencies they believe are necessary for their work. Boundary spanners play a central role in navigating relationships among stakeholders and managing conflicts that may arise, which means these boundary spanners potentially hold a great deal of organizational influence (Friedman \& Podolny, 1992).

To accomplish this work, boundary spanners process and appropriately distribute information and serve as external representatives of their organizations (Aldrich \& Herker, 1977; Tushman \& Scanlan, 1981); therefore, boundary spanners should have expertise in selecting, transmitting, and interpreting information, as well as the ability to find a compromise between potentially conflicting internal and external organizational policies (Aldrich \& Herker, 1977). Williams (2012) aptly describes these individuals, their positions, and their work: 
Boundary spanners are archetypal networkers operating in the social interstices of the organizational space. They represent thick nodes radiating connections both within their organization and to and from others in a web-like or reticular fashion. These connections form a rich information highway in which [they] occupy a pivotal role as intermediaries able to folder, direct, subvert, dilute, and channel the nature and flow of information which span multiple communication boundaries. (pp. 58-59)

Within the context of collaborative and networked environments, there is obvious potential in individuals and positions who can effectively function as informational intermediaries and support advancement toward shared goals across organizational boundaries. Notably, boundary spanning's potential benefits are equally important internally across units among larger, more complex organizations and systems. This study's focus is boundary spanning that connects universities and their communities, yet these competencies may be applicable to internal institutional priorities as well.

There have been multiple attempts to categorize boundary spanning. Most recently, Van Meerkerk and Edelenbos (2018), whose research on boundary spanning is situated within public management and governance, suggest a typology of four distinct boundary spanning profiles: fixer, bridger, broker and innovator (p. 111). Similarly, Williams (2012), whose research is situated in the public domain focusing on collaboration in public policy and practice, provides his typology, which includes the four roles of reticultist, interpreter/ communicator, coordinator, and entrepreneur (p. 58). Table 1 provides descriptions of their boundary spanning profiles and demonstrates similarities in the two typologies.

Such typologies provide a heuristic for more in-depth inquiry; however, the roles are neither absolute nor mutually exclusive. As such, a clear delineation of competencies across profiles may not exist. For example, Williams (2012) includes communication as a core competency for both the interpreter/communicator type and the coordinator type. Scholars and nonscholars alike would indeed observe the need for effective communication across each profile and type in practice. Nonetheless, critical nuances may exist with the need to further refine the specific competencies for each type. Van Meerkerk and Edelenbos (2018) note, "boundary spanners with different profiles perform different types of boundary spanning activities" and may "complement one another" (p. 111). Moreover, the profiles are not mutually exclusive; various situations and contexts may require a professional boundary spanning to shift their dominant profile according to the particular needs encountered.

The investment in and relative importance of the work of boundary spanners can vary depending on the degree to which an organization recognizes and values the work of boundary spanners (Aldrich \& Herker, 1977). However, even if an organization claims to value boundary spanning as an official function or role, that does not necessarily mean that the organization has the means or capacity to provide the requisite training and professional development opportunities. Williams (2012) suggests "boundary spanners occupy very powerful and influential positions" that exist beyond their formal roles in the organization and must "earn 

Table 1. Comparison of Van Meerkerk and Edelenbos (2018) Boundary Spanning
Profiles and Williams (2012) Boundary Spanning Roles and Competencies

\begin{tabular}{|c|c|c|c|c|}
\hline $\begin{array}{l}\text { Van Meerkerk \& } \\
\text { Edelenbos (2018) }\end{array}$ & Fixer & Bridger & Broker & Innovator \\
\hline Competencies & $\begin{array}{l}\text { Solving problems } \\
\text { in cross-boundary } \\
\text { endeavours, } \\
\text { aligning } \\
\text { organizational } \\
\text { policies with } \\
\text { external processes }\end{array}$ & $\begin{array}{l}\text { Creating } \\
\text { connections between } \\
\text { people from different } \\
\text { organizations, } \\
\text { promoting } \\
\text { cross-boundary } \\
\text { endeavours }\end{array}$ & $\begin{array}{l}\text { Facilitating and } \\
\text { mediating concrete } \\
\text { interactions; } \\
\text { dialogues among } \\
\text { actors with different } \\
\text { interests and } \\
\text { organizational } \\
\text { background }\end{array}$ & $\begin{array}{l}\text { Explores new } \\
\text { ideas, products and } \\
\text { processes crossing } \\
\text { public, private, } \\
\text { and societal } \\
\text { boundaries, } \\
\text { looking for } \\
\text { opportunities to } \\
\text { develop support } \\
\text { and mobilize } \\
\text { resources for } \\
\text { proposed } \\
\text { initiatives }\end{array}$ \\
\hline $\begin{array}{l}\text { Williams } \\
(2012)\end{array}$ & Reticultist & $\begin{array}{c}\text { Interpreter/ } \\
\text { Communicator }\end{array}$ & Coordinator & Entrepreneur \\
\hline Competencies & $\begin{array}{l}\text { Networking, } \\
\text { political } \\
\text { sensitivity, } \\
\text { diplomacy, } \\
\text { bargaining, } \\
\text { negotiation, } \\
\text { persuasion }\end{array}$ & $\begin{array}{l}\text { Interpersonal, } \\
\text { listening, } \\
\text { empathizing, } \\
\text { communication, } \\
\text { sensemaking, trust- } \\
\text { building, conflict } \\
\text { management }\end{array}$ & $\begin{array}{l}\text { Planning, } \\
\text { coordination, } \\
\text { servicing, } \\
\text { administration, } \\
\text { information } \\
\text { management, } \\
\text { monitoring, } \\
\text { communication }\end{array}$ & $\begin{array}{l}\text { Brokering, } \\
\text { innovation, whole } \\
\text { systems thinking, } \\
\text { flexibility, } \\
\text { lateral thinking, } \\
\text { opportunistic }\end{array}$ \\
\hline
\end{tabular}

Note: This table integrates adaptations from tables included in Williams (2012) and Van Meerkerk and Edelenbos (2018).

the legitimacy, autonomy and freedom" (p. 59) to act outside of standard organizational rules and conventions. Therefore, it is essential to develop a better understanding of the knowledge, skills, and abilities necessary for boundary spanning activities that occur beyond the official function and scope of an organizational member, such as a faculty member in the case of HECE.

\section{Boundary Spanning in Higher Education Community Engagement}

The literature on boundary spanning in the public sector provides a broad framework from which we can glean insight into higher education; however, distinct disciplinary research bases exist for public and higher education leadership due to the differences in context, actors, and purpose. In the context of higher education community engagement, boundary spanning refers to the work that is critical in overcoming the divide between the institution and the community 
(Weerts \& Sandmann, 2010). Boundary spanners need to be knowledgeable of the language, priorities, and needs of the community and the institution and be able to communicate between both sets of stakeholders. To shepherd their projects and partnerships effectively, these faculty members need to operate effectively within and between multiple organizations, which can be identified through members and nonmembers (Aldrich \& Herker, 1977). Weerts and Sandmann (2010) described boundary spanners in higher education community engagement as those who are tasked to represent the community in the university and to represent the university in the community. Therefore, these individuals need to be well-versed in the language, priorities, and needs of the community and the university. Faculty members who participate in community-engaged scholarship are often asked to find ways to build a bridge between the community and university through mutually beneficial partnerships. Informed by Friedman and Podolny (1992), Weerts and Sandmann's (2010) original boundary spanning model for higher education community engagement places individual roles along two axes, one being their primary focus (institutional vs. community), and the other being the nature of their tasks (technical/practical vs. socio-emotional/leadership). By overlaying these two axes, four roles of boundary spanners emerge: Community-Based Problem Solver; Technical Expert; Engagement Champion; and Internal Engagement Advocate (see Figure 1 for additional detail).

Of the four types identified by Weerts and Sandmann (2010), the community-based problem solvers and technical experts tend to come from the faculty ranks. The communitybased problem solvers are more likely to be clinical faculty members and are typically "on the front lines of making transformational changes in communities; they typically focus on problem support, resource acquisition, and overall management and development of the partnership" (Weerts \& Sandmann, 2010, p. 643). Community-based problem solvers may also feel conflicted in their roles because, even if they are formally members of the university community, a great deal of their work happens directly in partnership with the community. Technical experts are primarily traditional disciplinary-based faculty members who may use disciplinary or academic approaches to address community problems. However, jargon may often lead to difficulty in translating the analytic methods and results of the research.

Since it was first applied to higher education community engagement, boundary spanning work has also been investigated from the perspective of community partners (Adams, 2014) in the context of the work of community-engagement professionals (Dostilio, 2017; Van Schyndel et al., 2019) and through the influence of organizational characteristics on boundary spanning activities (Mull, 2016). An instrument has also been developed to operationalize the boundary spanning framework and associated behaviours (Sandmann et al., 2014).

Empirical evidence is necessary to better understand the development of competencies needed for boundary spanning individuals (Aldrich \& Herker, 1977); however, boundary spanners often operate in a "third space" between academic and professional domains (Whitchurch, 2013), making the conceptualization of boundary spanning not easily categorized. Whitchurch's (2015) conceptualization of the third space professional reflects the roles that integrate traditional academic and professional positions "no longer containable within firm boundaries" (p. 3). Frameworks like the SOFAR Model (Bringle et al., 2009) demonstrate the 


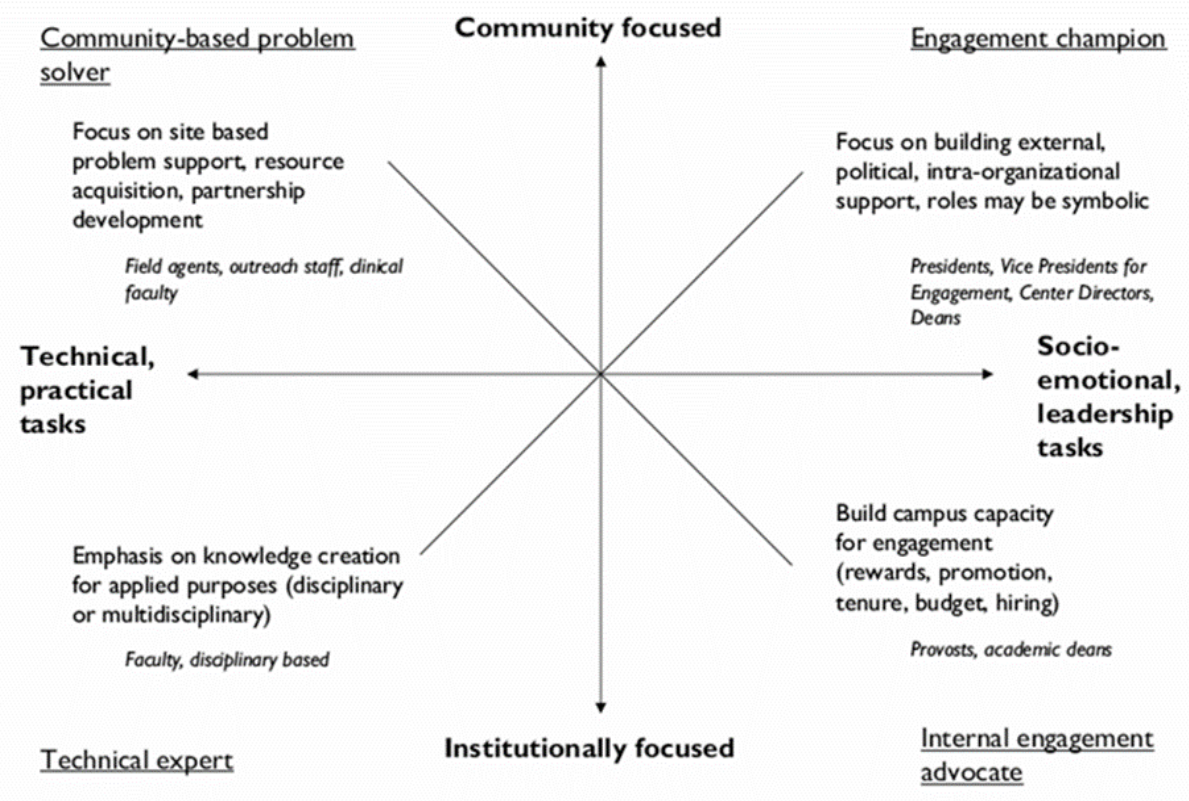

Figure 1. Weerts \& Sandmann (2010) Boundary Spanning Model

complexity of the interactions involved in community-university partnerships, suggesting that the total work of boundary spanning is not limited to one professional category. The Bringle et al. (2009) SOFAR Model recognizes "the relationships between students, organizations in the community, faculty, administrators on the campus, residents in the community (or, in some instances, clients, consumers, or special interest populations)" (p. 5). So, while we recognize that many individuals on campus engage in boundary spanning work (Weerts \& Sandmann, 2010), the current exploratory research is purposefully limited to the faculty's boundary spanning work. Several competency models in the extant literature address the knowledge, skills, and abilities necessary to support and do the work of community engagement discussed in the following section (see Blanchard et al., 2009; Doberneck et al., 2017; Dostilio, 2017; McReynolds \& Shields, 2015; Suvedi \& Kaplowitz, 2016).

\section{Faculty Development for Higher Education Community Engagement}

The literature on HECE reflects a growing interest in how community-engaged faculty and professionals are developed. In 2009, Blachard et al., in collaboration with the CampusCommunity Partnerships for Health, identified fourteen competencies for communityengaged faculty members that were organized by degree of proficiency (e.g. 2 novice, 1 novice to intermediate, 4 intermediate, 2 intermediate to advanced, and 5 advanced). More recently, McReynolds and Shields (2015) provided a multicomponent heuristic that organized fourteen competencies, each with a 3-stage proficiency scale including novice, intermediate, and advanced. McReynolds and Shields (2015) also organized the fourteen competencies into four distinct profiles related to HECE: organizational manager, institutional strategic 
leader, community innovator, and field contributor. They further suggest that core functions of professionals in HECE, including community-engaged faculty, include reflection, education, and communication, which they posit is "foundational to serving as a boundary spanning unit or professional" (p. 14).

Originally developed specifically for front-line extension staff, positions which notably are recognized as public service and outreach faculty within some universities, Suvedi and Kaplowitz's (2016) Core Competency Handbook for Extension Staff provides another reference point for this study. Their list of competencies was developed by surveying fieldbased extension professionals in Cambodia, India, Malawi, and Nepal. The thirty-three competencies they identified are organized by four task-related categories: program planning, program implementation, program evaluation, and communication and informational technologies (Suvedi \& Kaplowitz, 2016). These practitioner-oriented competencies reflect the essential application-oriented elements of HECE that are inconsistently integrated into graduate education (Austin \& McDaniels, 2006; O’Meara \& Jaeger, 2006), which perpetuates inadequate preparation and proficiency gaps among faculty members produced by some traditional doctoral programs of study.

Similarly, Dostilio and her research team (2017) present a competency model for identifying the second-generation community engagement professional (CEP). CEPs, in comparison to first-generation engagement staff, represent a more professionalized, refined, and distinct scholar-practitioner role that provides vision, leadership, and support for HECE. Their Preliminary Competency Model for Community-Engaged Professionals (Dostilio, 2017) aligns knowledge, skills and abilities, dispositions, and critical commitments with six areas they suggest are encompassed by the CEP role: leading change within higher education; institutionalizing community engagement on a campus; facilitating students' civic learning and development; administering community engagement programs; facilitating faculty development and support; and cultivating high-quality partnerships. We have previously suggested the Weerts and Sandmann (2010) Boundary Spanning Model's value as a supplement and potential area of integration with the Dostilio et al (2017). CEP Competency Model (Purcell et al., 2019). Notably, Doberneck et al. (2017) address previously identified gaps in academic and professional HECE development within graduate education. Their work at Michigan State University as scholar-practitioners affiliated with the university's Graduate Certificate in Community Engagement resulted in a competency model that synthesizes multiple competency models and has undergone numerous iterations. Doberneck et al.'s (2017) competency model is promising, particularly as scholars continue to explore their model's applicability across institution types. As evidenced by the continued interest and depth of research in competencies related to HECE, this area of inquiry remains relevant and timely.

\section{Situating the Current Study}

Our research adds to this literature by explicitly identifying the competencies necessary for community engagement through the lens of boundary spanning. We expect that through the application of boundary spanning as a conceptual framework, individuals expected to serve in 
boundary spanning capacities will better understand the expectations of their positions, and in turn, be able to identify professional development opportunities to meet those expectations. Further, in recognition that community-engaged faculty members are not a monolithic group (Morrison \& Wagner, 2017), we believe that this exploratory work will be an initial step in better understanding the many ways to support and develop faculty members. Recent volumes dedicated to the development of community-engaged faculty members (Berkey et al., 2018; Welch \& Plaxton-Moore, 2019) demonstrate that the interest in faculty development is a critical activity for institutions dedicated to the principles of community engagement (Welch \& Saltmarsh, 2013) and can serve as a pathway to empowering faculty members to do community-engaged work (Welch \& Plaxton-Moore, 2017).

For community engagement to become fully institutionalized, it should be integrated throughout the core functions of the college or university (Fitzgerald et al., 2012), including being placed "on the desk" of faculty members who make community engagement central to their scholarly agenda (Sandmann, 2009). However, the faculty members who engage in this work may be asked to manage contrasting interests and desired outcomes of multiple stakeholders, both internal and external to the university (Friedman \& Podolny, 1992; Weerts \& Sandmann, 2010). Navigating these potential conflicting roles adds to the complex work of community-university engagement.

Boundary spanning (Friedman \& Podolny, 1992; Weerts \& Sandmann, 2010) serves as a framework through which faculty members can develop the skills necessary to navigate these complex relationships effectively. This exploratory study seeks to identify the required competencies for community-engaged faculty members to perform in boundary spanning roles. As commitments to HECE grew on university campuses and resources were redirected to community engagement initiatives, research on the faculty role began to increase. An initial focus on course-based service-learning expanded to community-engaged research and later toward faculty motivations and rewards within the existing performance metrics of promotion and tenure (Van Schyndel et al., 2019).

The increase in HECE activities and subsequent increase in resource allocations toward those activities gave way to a new academic professional role: the community-engaged professional (Dostilio, 2017). Incarnations of this role function in myriad administrative and leadership roles at varying managerial levels across institutions and the position is now not necessarily filled by what has historically been recognized as a typical faculty member. As demand for higher education increases globally, it comes as no surprise that institutions have come to rely more heavily on instructors who do not comprise the traditional instructional corps. Part-time teaching faculty ranks have proliferated, as have the number of affiliated faculty appointments of qualified full-time staff and administrators. Therefore, caution should be given when categorizing faculty as a group since the professoriate's makeup continues to shift. For this study, faculty members included full-time, tenure-track and tenured faculty who have responsibilities for a combination of teaching, research, and professional service. 


\section{Purpose and Research Questions}

As posed by Weerts and Sandmann (2010), "future research focusing on values, preparation, and socialization of spanners could lead to a continuously developing, well-prepared pool of individuals able to skillfully act on the complex, multifaceted demands posed by engagement programs" (p. 653). Therefore, the overall purpose of this study is to identify and interview community-engaged faculty members on multiple higher education campuses to better understand their perceptions of their roles as boundary spanners, the expectations they have of their professional competencies, and how they are prepared to perform their boundary spanning roles successfully. Our specific research questions include: (a) In what ways do communityengaged faculty members describe their professional roles as "boundary spanning?" (b) What competencies do community-engaged faculty members identify as essential to their professional roles? (c) What competencies do community-engaged faculty members believe they possess in their professional roles? (d) In what ways do community-engaged faculty members feel their professional development in these roles could be supported?

\section{Research Methods}

As an initial exploration of faculty perceptions of their boundary spanning roles, this study's confidential qualitative data were collected via interviews with a purposeful sample of the population under examination. Interview questions were designed to uncover the participants' perspectives on boundary spanning within their professional roles, essential competencies for community-engaged work, and ways in which their community-engaged work could be supported. Because faculty members' experiences vary depending upon their contexts (e.g., university type, academic rank, discipline or field of expertise, etc.), the research team designed this pilot study as a precursor to an expanded, multiple case study research design to inform future research on community-engaged faculty. Data were collected under the approval of the Kennesaw State University Institutional Review Board for study \#18-461 and with the participants' explicit consent.

\section{Statement of Subjectivity}

As community engagement scholars who are currently or have previously served in administrative positions that support faculty pursuing community-engaged work, we came to this study with a professional bias toward integrating community partnerships in teaching and research. Likewise, we have experienced firsthand the difficulties of forming and maintaining sustainable partnerships with community members and integrating community-engaged pedagogy into new and existing curricula. While our experiences inform the study's design, we intend to critically examine faculty members' experiences and perceptions through methodologically sound and rigorous inquiry. As such, we acknowledge the integral role our collective expertise as qualitative researcher-practitioners has on our approach to the study and our sensemaking related to the data analysis and discussion. 


\section{Participants}

The participant sample for this exploratory study was purposefully limited and selectively randomized. We first identified three public institutions in which we had an existing entry point for recruiting a network of community-engaged faculty. We then contacted the community engagement and service-learning (CESL) unit director at each of the three institutions to request the names of six community-engaged faculty exemplars. As prospective participants criteria selection, we asked the unit directors to consider full-time, permanent, tenure-track and tenured faculty who are not currently serving in a traditional full-time administrative position (e.g. considered "teaching faculty"), demonstrated commitment to communityengaged teaching and research, had a record of publications related to community-engaged research and/or scholarship on engagement, and had received formal recognition in the form of university or national awards or award nominations. To further refine the purposeful technique, we encouraged the unit directors to consider faculty who were representative of the faculty diversity on campus.

We compiled an initial list of eighteen potential participants with the faculty members identified by the unit directors. We also conducted online searches of each possible participant to ensure they reflected the outlined selection criteria. At this point, we employed random selection among the pool of potential participants to identify two faculty members from each institution for a total of six participants. One alternate participant was also identified for each of the three institutions if a prospective participant declined to participate.

To control for ethical considerations and potential conflicts of interest, real or perceived, we ensured interviewers and interviewees did not come from the same institution. The three researchers conducting this study were assigned two interviews with participants from different institutions with which the researcher is not affiliated. Each researcher contacted their assigned two participants via email with an introduction, overview of the study, and invitation to participate. Each of the six faculty members contacted agreed to participate in the research and confirmed informed consent. Our exploratory study's participant sample was limited to six individuals to provide sufficient data for analysis, while also allowing ample flexibility for any interview protocol refinements or broader modifications of the study deemed needed before expanding the research team and sample population for the full study. As a pilot study, our participants' demographics were not a central focus.

Additionally, due to the intentionally limited sample size, we were cautious about including demographic data at the risk of being too reductive. Therefore, this data was not collected and is not reported. However, we recognize there may be implications for various intersecting identities, which should be considered in future research.

Table 2 provides the faculty rank and academic discipline of the participants. Of the initial list of eighteen potential participants, only two faculty members had associate professor's rank. There were nine assistant professors and seven full professors. As such, the final randomized participant sample is appropriately reflective of the initial purposeful sample. 
Table 2. Participants Academic Rank and Discipline

\begin{tabular}{|c|l|l|}
\hline Participant ID & Academic Rank & Geography \\
\hline 1 & Assistant Professor & English \\
\hline 2 & Assistant Professor & Physics \\
\hline 3 & Professor & Nursing \\
\hline 4 & Assistant Professor & Art Education \\
\hline 5 & Professor & Literacy Education \\
\hline 6 & Assistant Professor & \\
\hline
\end{tabular}

\section{Data Collection}

Data points were collected remotely via one-on-one interviews conducted through web-based video conferencing technology. Interviews were selected over surveys or narrative reflections for the researchers to pose clarifying questions and probe further in real-time. Each interview was recorded and lasted approximately one hour. An open-ended interview protocol guided the semi-structured interviews informed directly from the boundary spanning literature, specifically the Weerts and Sandmann (2010) framework. In the first part of each interview, participants were asked to discuss their positions' essential functions, with a particular emphasis on understanding the relative balance between an institutional focus and a community focus and the relative balance between technical/practical tasks and socio-emotional/leadership tasks. Next, the interviews explored how well the participants perceive they are prepared to fulfill their various duties and the degree to which the focus and task orientations required of their positions align with their strengths and interests. Interviewees also discussed how various approaches to their professional development could address any gaps that may emerge. Following the interviews, recordings were transcribed and prepared for analysis. To support data reliability and validity, the researchers employed investigator triangulation and member checks, as appropriate, with interview participants.

\section{Limitations}

As noted previously, this exploratory study contributes to the foundation of a more comprehensive examination of boundary spanning competencies among community-engaged faculty; therefore, the study design intentionally limited the participant sample to a purpose pool of exemplar community-engaged faculty. Although the authors anticipate future research on the topic, the current study's intentional restraints are nevertheless limitations. Specifically, a larger pool of faculty members representing a broader diversity in demographics among participants and the institutional types represented will strengthen the research moving forward. Additionally, while potential participants were identified through an initial round of purposeful sampling, they are potentially self-selecting. Not all faculty whose work engages in community partnerships are recognized within their institutions - the phenomenon has 
been documented by scholars and practitioners seeking to measure and monitor communityengaged activity across campuses. Likewise, the current study design does not account for faculty members uninterested in or dissuaded from pursuing community-engaged work.

\section{Data Analysis}

Merriam (2009) posits "all qualitative data analysis is primarily inductive and comparative" (p. $175)$; therefore, the constant comparative method is appropriate even when researchers are not conducting grounded theory research. As such, data were analyzed via open coding utilizing a continuous comparative method (Glaser \& Strauss, 1967; Merriam, 1998; Ruona, 2005). After transcripts were prepared, each researcher reviewed their interview files for accuracy and clarity. The researchers then reviewed and coded the interview files independently through an open coding process to identify categories and themes that emerged from the initial analysis. At this point, the researchers convened to discuss their coding schemes and to develop a consistent code set to be used for the second round of individual coding. The first round of individual coding yielded eighty-two (82) codes. The group review and discussion process yielded seventy (70) agreed upon codes falling under six themes for the final coding key. Table 3 provides an overview of the themes and related codes.

\section{Table 3. Data Analysis Coding Themes and Frequency of Application}

\begin{tabular}{|l|c|c|}
\hline Code Themes & $\begin{array}{c}\text { Number of Unique } \\
\text { Codes }\end{array}$ & $\begin{array}{c}\text { Codes Application } \\
\text { Frequency }\end{array}$ \\
\hline The Boundary Spanning Role & 9 & 178 \\
\hline $\begin{array}{l}\text { Competencies (Knowledge and } \\
\text { Skills) for Boundary Spanning }\end{array}$ & 16 & 139 \\
\hline $\begin{array}{l}\text { Motivations and Dispositions } \\
\text { Supporting Boundary Spanning }\end{array}$ & 11 & 53 \\
\hline Professional Identity/Persona & 6 & 36 \\
\hline $\begin{array}{l}\text { Situational Factors and Context } \\
\text { Impacting Boundary Spanning }\end{array}$ & $\mathrm{n}=70$ & 57 \\
\hline Process-Related Concerns & & $\mathrm{n}=643$ \\
\hline $\mathrm{n}=6$ & & \\
\hline
\end{tabular}

The researchers applied Ruona's (2005) qualitative data analysis method that utilizes Microsoft Excel Spreadsheets and the table function in Microsoft Word for organizing data sets for coding. A variety of data analysis programs are available; however, the method selected leverages a widely available word processing program, requires no additional cost for the researchers, and can be adopted readily without additional software training. The accessibility 
of this data analysis method is particularly appealing to us as community-engaged researchers who are mindful of adopting and demonstrating research methods and tools that may be easily implemented in research partnerships with community partners and students. This method enabled the research team to merge their independently completed coding files, and comments to a master coded data set. The coding process resulted in thirty-three (33) pages of coded data containing six hundred and forty-three (643) unique code applications. In the following section, data excerpts illustrate the findings informed by the described data analysis process.

\section{Findings and Discussion}

The purpose of this study was to better understand the role of community-engaged faculty in their formal and informal boundary spanning leadership roles, including the competencies associated with the roles. Data analysis revealed there is generally overlap between the competencies interviewees identified as essential and those they believe they already possess. Therefore, research questions two and three were combined into a revised research question: In what ways do boundary spanners define their competencies?

\section{The Role of Boundary Spanning Faculty}

Boundary spanning faculty describe their professional roles as problem-solvers, integrated experts, and relational facilitators. Consistently, participants recalled motivations for their work as being centred around needs and related opportunities. These needs were representative of myriad stakeholders included in campus-community partnerships. For example, these faculty members sought to address gaps related to student learning, community needs, and their respective fields of inquiry. Likewise, their boundary spanning included an integrated approach that leveraged their faculty positions' core responsibilities and related skill sets. Unsurprisingly, participants also emphasize their facilitative roles and the importance of relationship building for community-engaged endeavors.

Participants emphasized problem-solving and technical expertise consistently in their descriptions of their community-engaged role, consistent with Weerts and Sandmann's (2010) technical and practical orientated roles. Similarly, they described activities consistent with those typical of engagement champions and internal engagement advocates; however, there was less distinction in their description of the socioemotional and leadership tasks. These findings align with current research on academic leadership. For example, studies indicate it is common for faculty to have greater proficiency in technical and practical task related to their research and teaching as compared to the leadership tasks associated with the engagement champion and internal engagement advocated roles identified by Weerts and Sandmann (Buller, 2014; Gmelch \& Buller, 2015; Kezar \& Lester, 2011; Ruben et al., 2017). Participants in this study described their boundary spanning roles as that of problem-solver (aligns with communitybased problem solver), integrated expert (aligns with technical expert), and relational facilitator (aligns with engagement champion and internal engagement advocate). 


\section{Problem-Solver}

As researchers and educators, faculty members are trained to identify gaps. Gaps in the literature and student learning serve as opportunities for expert contributions and problem-solving. One faculty member remarked on the need for consistent evaluation and problem-solving. They said, "Being an art teacher for so long has really given me the ability to problem solve when the inevitable snafus come up, when you're doing the projects themselves. You can kind of build the plane and fly." Similarly, another participant provided an example of community-based problem-solving strategies. They reflected:

We cultivate these longer-term relationships with individuals and members of the different community organizations, and we work with them to help identify what it is that we can lend our research expertise to; what problems and issues are they interested in us partnering with them on to help them better understand and to help them figure out, okay, if this is an issue that the community has identified, what are some potential interventions that we can discover that would be helpful in overcoming that particular issue.

The faculty member continued,

[Faculty colleagues] were identifying what are the problems for the community. One is over-reliance on emergency rooms and under-reliance on primary care and preventative care. Through all these qualitative focus groups, interviews, surveys, we were all out in the community helping with the project. Ultimately, we were able to identify, okay, what are the barriers, and we were able to figure out, let's try some interventions. These were all in partnership with the community themselves. They were involved as equal partners at every stage of the research. Then once we tried implementing the interventions, we eventually saw that, okay, and we were able to document emergency room use is declining and preventative care, primary care use is increasing. That was one thing that informed my thinking about this.

This faculty member illustrates the collaborative nature of problem-solving in community engagement and the dual roles of content expert and process facilitator that boundary spanning faculty leaders often fill.

Participants also described problem-solving related to issues internal to their institutions. One faculty member presented their community-engaged teaching as a problem-solving mechanism for students' 21st-century's civic education (Longo \& Shaffer, 2019). In discussing the value of service-learning projects, they argued, "In the end, this is just a tool kit that you are learning and acquiring that one day you will put this tool kit to work, to the benefit of humankind basically, to build civilization." Another faculty member recalled how the collaborative aspect of community engagement forced colleagues to transcend internal communication silos. They recalled: 
The teachers in this [geographic] area are looking to us as a center for science education and professional development particularly. We had done this in combination with the science education folks over here on our campus to build bridges, more bridges, between content and science education between the people and content people. There needs to be more cross-talk.

In this instance, measures had been implemented to alleviate known problems for internal communication, yet the faculty member lamented their progress's inadequacy. Nonetheless, their community-engaged work supported much needed internal solutions necessary for external impact with the partnering school district. Weerts and Sandmann (2010) suggest individuals may transition in and out of specific boundary spanning roles depending upon current needs; therefore, we anticipated hearing examples of participants' experience with such dual roles and transitions. However, we noted inconsistent evidence of institutional support to cultivate the skills required for these roles.

\section{Integrated Expert}

Faculty participants clearly recognized their integrated role as content experts and emerging process experts. Faculty workloads typically include teaching, research, and service with varying degrees of combination and integration. Participants emphasized the overlap of their workload areas concerning community-engaged work and their related boundary spanning leadership roles. One faculty member remarked candidly, "There's blurry lines all over the place." Another faculty member described the phenomenon of expertise integration as critical to their success as an academic. They noted:
A lot of my research and scholarship needs to align with my teaching and my administrative roles, so in this next year, a lot of my writing is about, how do we develop and administer community engaged projects? Community engaged leadership roles? And so I think there's a crossover there, right? Both from the...I'm writing about the work that I do and constructing projects about the work that I do to demonstrate to others how you're going to be able to do this. I mean, I think if I wasn't able to write about the teaching and administrative facet of my work, I don't know how I would be able to keep a pretty rigorous research agenda.

And still, one faculty member explained the challenges of integrating their work. They commented, "I am a researcher at heart, and that is the part that is the most challenging; when you have a heavy service and administration load." They also described the difficulty of balancing service and administrative assignments with research and teaching. This sentiment was echoed by another faculty member with a dual administrative appointment. They acknowledged challenges in how they reported their work during annual reviews and for promotion and tenure: 
I also find that service takes a fair amount of time because of how much I work with students on community-engaged projects and internships, and so I write a lot of letters of recommendation, and I spend a lot of time helping students get materials together. That brings me very closely to administration. I work hard to try to shift as much of that service into the administrative category, recognizing that my responsibility as the [community engagement faculty coordinator] is largely to help our students develop the kind of professional skills and needs that allow them to move on from [their undergraduate] program, whether it's their minor or their major, into industry or into graduate programs. It's a very fine line, and so sometimes I find it falls under administration. Sometimes I find it falls under service.

Promotion and tenure guidelines typically include specific guidelines for workload arrangement for faculty members, detailing their assigned efforts toward teaching, research, and service, including expected deliverables for each area.

Variations in faculty workload models may allow for increased focus on professional service, but are not necessarily rewarded (O’Meara, 1998). On the contrary, institutionalized barriers actively deter faculty members from community-engaged research, teaching, and professional service (O’Meara, 2008b; O’Meara, 2011; O’Meara \& Jaeger, 2006). As hybrid facultyadministrative positions proliferate in response to expanding institutional commitments, boundary spanning faculty must engage their non-community-engaged counterparts and academic leaders in dialogue on the purpose and value of community engagement integrated workloads, including explicit support and recognition of their efforts and subsequent scholarly products. Such commitments at the department and institutional level must exist in both policy and practice.

\section{Relational Facilitator}

Finally, participants described their facilitative role as boundary spanners. One faculty member emphasized the importance of consistent presence in their facilitative role. They said:

Maintaining networks of people in the community, and that is partly fostered through some of the grant work, but it's also just showing up for events... You're always going to people's events, other partners' events and things like that, and really nurturing. Taking the time and knowing that nurturing relationships, in that way, is really important.

Another faculty member described the essential role of relationship building in the facilitative role. They recalled: 
I think much of my work and my background in community engaged worked, whether it's community writing or service learning, or just civic engagement based partnerships, or for teaching purposes, has been very grassroots, very organic, very one person at a time, or five people at a time, and that idea of doing that then yields more... Yields greater growth.

Operating beyond one's comfort zone was described as another essential component of boundary spanning faculty leadership in community engagement. For example, one participant commented:

I'm just not one who spends a lot of time announcing or promoting or putting myself in a very public space about the work that is done, and that just might be very much my personality. But I'm starting to realize how essential it is that I really start to focus on highlighting the work that other faculty members, and that students, and that I do in this area, in developing the kinds of things that share the value of this work, share how powerful and essential this work is for 21 st century students and 21 st century higher education.

Likewise, another faculty member noted, "I went out personally and shared the goal of the program that I was doing and asked individuals if they were interested in coming on board."

These examples of socioemotional and leadership tasks characterize the engagement champion and internal engagement advocate roles; yet, the duties are essential, integrated functions of the boundary spanning faculty whose role is typically associated with the technical expert. This observation suggests the boundary spanning roles previously identified by Weerts and Sandmann warrants a revision to reflect the shifting dynamics, contexts, and expectations of boundary spanning faculty. Dostilio (2017) recount the continued professionalization of staff roles related to community engagement with data informing the comprehensive Competency Model for Community Engagement Professionals (CEPs). Just as staff roles have developed into their "second-generation professionals" (Dostilio \& Perry, 2017, p. 9), boundary spanning faculty roles have similarly transformed (Welch \& Plaxton-Moore, 2019).

Welch and Plaxton-Moore $(2017,2019)$ offer a holistic framework for professional development to advance community engagement that is built upon a comprehensive and inclusive view of educational development inclusive of multiple stakeholders (faculty, students, administrators, and community partners) and contexts (higher education and academic disciplines, institutional, classroom, and community). Their meta-model provides a holistic representation of educational development for community engagement. Further, it illustrates advancements within the field of scholarship on engagement, including the roles and competencies required to sustain university-community partnerships and community-engaged teaching and learning. Situated among these more recent competency models for community engagement, this study of boundary spanning faculty is a relevant, timely, and focused addition to the literature that illustrates the need for ongoing research specific to faculty. 


\section{The Competencies of Boundary Spanning Leadership Among Faculty}

The Boundary Spanning Model recognizes various skills associated with boundary spanning tasks; whereas, more recent models address requisite competencies, which encompass knowledge, skills, and attitudes or dispositions (Dostilio, 2017, p. 29). A focus on competencies honours the value commitments undergirding tasks associated with a given role. Furthermore, degrees of potential development and refinement of skill reflective of ongoing practice, educational development, and attention toward the perfection of one's work is inherent to a competency. The faculty members interviewed in this study provided similar perspectives on the competencies required of boundary spanning faculty members. Core competencies described by the faculty participants include developing an integrated scholarly agenda, awareness of community engagement principle or best practices, and the ability to manage complex projects effectively.

\section{Expressions of Meaning and Purpose}

O'Meara (2002) found that faculty decisions to adopt community-engaged practices were informed by three sets of values: institutional, scholarly/discipline-oriented, and individual. In their discussion of required competencies, faculty participants reflected on their motivations for engaging with their communities. Their boundary spanning activities reflected each of the sets of values O'Meara (2002) identified. These motivations encompassed value-laden expressions of meaning and purpose. One faculty member shared:

I'll put it very simply; it's the love of your subject. It's what drives you and what it drives me and all of us professors. We are idealistic fools. I see these very highly capable people give themselves to a life of service...The basic competency is passion and love for what you [do] and mastery of your discipline. Taking great joy in the theater of life where we have the view of looking [into] the eyes of the next generation and seeing this caterpillar to butterfly transformation. I think these are just the basic elements of being a good educator.

Likewise, another faculty member reflected on their desire to be connected to the community in which they live and "feeling more than just being on the periphery." Another faculty member elaborated, "My life is very privileged, and I understand that, and so I feel like I have a duty to do what I can do to improve the communities that I live in."

Each participant emphasized the relevance of their community-engaged work as a motivator to lead and span boundaries. One faculty member argued:

My perspective is the work that we're doing as researchers should be impactful to the broader public. Otherwise, I feel like, what's the point? Not many people are going to pick up a peer-reviewed journal article and read it, let alone maybe even understand it, so I think it's important for us. We have to translate our work for the broader public for it to have a better chance of having a positive impact. 
They further clarified:

It's all about good people with similar interests with a passion for educating and education, connecting with each other, and that's how emergent, new unexpected structures will emerge. This is what happens in complex systems. Open and complex systems, not hermetically sealed and closed systems, but when the conditions are right you have emergence of ordered states come about and these ordered states would be better education. Lining up more effectively behind the compass of student success basically in the end. Shaping the next generation.

These altruistic ideals reveal the motivations behind the faculty members' boundary spanning leadership roles and their willingness to navigate community engagement's complexity and ambiguity. These values, attitudes, and dispositions also demonstrate how faculty make meaning of their work. Moreover, these responses align with competency-based models that include values, attitudes, and dispositions such as the work of Dostilio et al. (2017) and Welch and Plaxton-Moore (2017, 2019). Prior to the 2010 publication of their Boundary Spanning Model, Sandmann and Weerts (2008) noted, "Whether engagement will be adopted... depends on how it reflects the value system of the institution as a whole or the individuals within it" (p. 184). Individual and institutional values drive the mission, allocation of resources, evaluation, and rewards related to community engagement. Therefore, it is essential to understand how faculty may serve as effective and supported boundary spanners.

\section{Integrated Academic Strategy}

The data illuminate the importance of strategy with regard to a faculty member's research agenda, especially for those faculty engaged in boundary spanning. One participant reflected on their community-engaged research and publication strategy:

I was engaged in a relationship-driven, community-driven project as a core part of my research agenda, that wouldn't necessarily result in articles every year... I ended up having, from a pragmatic standpoint, I had to have multiple research projects going, where I could publish more frequently. And actually, for expediency's sake, to get through the promotion and tenure process, it had to be more research-driven, more driven by me...But there were shorter projects, less involved projects, but still relationship-driven, still co-developed, still community-driven, and so I was able to publish more frequently from those projects while I was engaging in the real in-depth projects. And then from that long-term, in-depth project, myself, a colleague, and then one of my community partners co-wrote an article that was published. 
Another faculty member advised:

Part of the requirement at the university is to integrate as much as possible those three, our service, our teaching, and our research - our scholarship. I think one competency would be to find ways, being prudent and finding ways of how to integrate them. Thinking smarter, if you will, of how to integrate them.

They further clarified their comment with an example of their efforts:

Integration of your research teaching and service is really important. So, you got to do all those things, but you also have to make sure that they're not going all off in different directions. For me, because my teaching load, it kind of necessitated that my research be about teacher education. But I also really care about that. So that kind of thing where you have some kind of symbiotic relationship among those three different things.

As previously discussed, clear articulation of faculty workloads and deliverables are critical for advancement in the professoriate. Likewise, demonstrating connections across one's teaching, research, and service are widely recognized hallmarks of satisfactory performance among faculty; however, complete integration remains a somewhat elusive yet permanent goal (Bloomgarden \& O'Meara, 2007). This finding, the necessity of an integrated academic strategy, suggests a common understanding and intentionality among effective boundary spanning faculty regarding their work. Specifically, each participant was aware of the need to integrate their performance areas (teaching, research, and professional service) in addition to their community engagement pursuits.

\section{Principles of Authentic Community Engagement}

Faculty participants shared multiple examples of best practices for community engagement as essential competencies. Interestingly, the faculty members provided values typically ascribed to leaders to describe what the researchers termed authentic engagement to delineate their work from practices informed by less altruistic foundations. For example, one faculty member noted, "Community engagement is a collaborative process... I think understanding that, that essential facet of community-engaged work and community-engaged scholarship, makes it very different." Other participants referenced humility, power and privilege, flexibility, and "interest in the human condition" as essential competencies of boundary spanning faculty leaders. One faculty member clarified:

Humility...being willing to give up power and control and being willing to be flexible and kind of let other people lead, who may not have a $\mathrm{PhD}$. And when people try to assert their supposed authority as an expert, being able 
to speak to that, and say that expert knowledge is created and developed in different ways... people who really see themselves as professors and as $\mathrm{PhDs}$ would probably struggle to do this kind of work. But people who are able to understand that there's so much knowledge in the world, and they don't have all that knowledge, and there's a lot of different ways to cultivate and grow and learn, and are willing to learn from others outside of the academy, then I think that they'll be successful.

The participants' reflection on the influence of power and privilege exemplifies a growing interest in critical approaches to community engagement (Bruce, 2013; Butin, 2015). Their perspectives mirror the desire for authentic community engagement identified among health professional educators and community partners by Kline et al., (2018) that would appropriately honor the knowledge, skills, and traditions of community-based "experts by lived experience" (p. 79). Not surprisingly, the study participants reported essential values and dispositions that were evident in their existing practice. While our sampling method specifically sought established, accomplished faculty leaders in the field, the current study design does not address how the research team may identify competencies with which the participants are unfamiliar. That is, how we might support the identification of blind spots or what the participants do not realize they do not know.

\section{Contextualized Project Management}

Faculty members receive training for research-related project management as graduate students through their thesis and dissertation projects, equipping them with relatively transferable project management skills. However, community engagement work may involve contextualized project management skills for which a faculty member has no familiarity or competency (Bloomgarden \& O’Meara, 2007). Therefore, we were not surprised that such skills surfaced as an essential competency for boundary spanning faculty leaders. Participants revealed perceived inadequacies among professors in this domain linked to insufficient training as doctoral students and early career faculty. Consistently, participants shared examples of muddling through the process and learning via experience. In two cases, the faculty members had a relevant background and experience organizing complex, collaborative projects, which provides a helpful contrast for understanding professional development needs for current and prospective boundary spanning faculty leaders. For example, one participant explained the benefit of their professional background before entering the academy:

I think one of the things that allows me to do this job with some competence is frankly that I do have a background in project management, understanding how to juggle a lot of things, develop a strategic plan, modify a plan. I think that is essential for doing this kind of administrative work. Especially this kind of administrative work where you're moving between the community and the university. Those are two very different groups. 
Conversely, another participant described their informal strategies for professional development:

I think this is an area that I continue to work and tweak. Continue to seek best practices. Seek wisdom from mentors about how to really prioritize the pieces of large projects. I think that continues to be the area that I focus on and am seeking to grow and get better at. To actually deliver on many of the goals.

Faculty members are conceivably competent in basic project management principles; however, community engagement adds additional layers of complexity and nuance that require attention.

Armitage and Levac (2015) suggest additional training should be integrated into doctoral programs to better prepare future faculty. Their primary concern was training related to the "principles and processes, and methodological and theoretical orientations of CES" (Armitage \& Levac, 2015, p. 149), of which community engagement project management would be an essential criterion. For example, depending upon the disciplinary background and institutional affiliation, a typical faculty member may be unaware of campus units charged with supporting community-engaged scholarship and teaching. Therefore, early exposure to communityengaged research methodologies and pedagogies would increase a future faculty member's awareness of available resources and aspects informing community engagement project management and, subsequently, their boundary spanning role.

\section{Cultivating and Supporting Boundary Spanning Faculty}

Participants discussed the competencies needed among boundary spanning faculty leaders and provided insight on the support they had received and still require. The data revealed two themes related to professional development for boundary spanning faculty leaders. First, faculty members recognize their need for professional development and institutional support of their work. One faculty member shared their need for "a deliberate strategy in order to grow as a professional in this area." This intentionality in professional development is in contrast to one faculty member's unintentional growth through trial and error. They reflected on the correlation of experience, competency, and expansion of the field. One participant stated candidly, "As the work continues to grow, my capacity is not where it was." Dostilio et al. (2017) addressed this reality in presenting their competency model as "preliminary" as the assertion that additional interactions are anticipated as the knowledge base grows and contexts shift. Likewise, this study reflects ongoing efforts to advance our understanding conceptually and refine practice among ourselves and our colleagues.

We agree that competency-based educational interventions should be a priority for community-engaged faculty and institutions moving forward. Welch and Plaxton-Moore (2018) note "competency-based professional development incorporates specific knowledge, skill sets, and attitudes deemed as salient attributes for competent professional performance" (p. 38), and we recognize significant similarities in required competencies among faculty and CEPs. We also 
believe there may be unique contextual variables and performance expectations among faculty that may need differentiated or additional competencies to fulfill responsibilities and commitments. Second, mentoring is essential for cultivating and supporting boundary spanning faculty. Participants shared the impact of their own faculty and peer mentors in guiding them to pursue community-engaged work and to develop their boundary spanning identity and competencies. One participant commented, "I think identifying mentors that are at that next level is essential now... the wisdom of some additional mentors, one or two, would really help me best serve the department and [university]... I think that's essential." Likewise, existing boundary spanning faculty have an opportunity to cultivate the next generation of community-engaged faculty. One participant shared their desire to support others:

I'm hoping too that as I work alongside my other faculty members, that they too will see or develop that same passion as I did from others... we always have to think about the ones who will come behind us. I'm hoping that it can be a torch bearing for them to see the importance of just always giving back.

Participants indicated their professional and disciplinary legacy with respect to their colleagues, students, and community partners was an important consideration.

\section{Implications for Future Research}

This exploratory study provides a conceptual foundation for continued investigations of competencies among boundary spanning faculty. Just as the CEP has emerged as a distinct professional role with specific competencies, members of the professoriate have historically claimed specific roles, functions, and privileges (e.g. academic freedom). However, higher education has shifted significantly in recent decades along with the faculty's composition, including specific position types and performance expectations. As community and institutional contexts change and faculty roles change, it behooves us to re-examine past frameworks for continued relevance and application. The Boundary Spanning Model and the faculty and professional roles associated with it warrant such a review if the model maintains its utility for scholars and practitioners alike.

The scholarship of Doberneck et al. (2017) suggests there is notable potential for coursebased competency development for graduate students; however, we do not yet have evidence of such revised competency-based educational interventions among current faculty. The CES Competency model developed by Blanchard et al. (2009) is another example of seminal work that warrants a review due to widespread changes in professional, organizational, social, and political variables that impact the work of community-engaged faculty. Our exploratory study begins this inquiry and provides a conceptual foundation from which others interested in boundary spanning may pursue additional research. We envision a renewed interest in the Boundary Spanning Model and note the following implications for future research.

Due to the emergence of new roles (e.g., the CEP) and greater opportunity for faculty to serve in hybrid administrative roles to support community engagement, we first recommend 
a reassessment of the existing Boundary Spanning Model. The reassessment should explore formal and informal roles and the competencies associated with each role. Such inquiry may yield a boundary spanning competency inventory that includes general boundary spanning competencies and targeted, role-specific competencies. We must continuously challenge ourselves and community-engaged scholars to integrate community partner perspectives, and a revision of the Boundary Spanning Model is an ideal opportunity. Weerts and Sandmann (2010) offer, "Some community partners were keenly aware of the skills required to succeed in working with the community and could identify who was most capable of filling these roles" (pp. 645-646). It is therefore incumbent upon scholars to pursue research collaborations with our community partners.

Second, we anticipate the emergence of more nuanced insight regarding applying the boundary spanning framework in practice. For example, when, why, and how do individuals transition into different roles, particularly informal roles? Based upon our preliminary data analysis and findings related to perceptions of authentic engagement, researchers might consider metrics for success as related to the competencies of boundary spanners as compared to indicators of an engaged campus (see Beere et al., 2011; Gavazzi \& Gee, 2018; Percy et al., 2006; Saltmarsh \& Hartley, 2011; Welch, 2016). For example, are metrics for various roles shared across stakeholder groups and do they align with individual and institutional values? Congruence among these values and goals are necessary for long-term sustainability and subsequently, the advancement and integration of higher education community engagement.

Third, as we examine the career arc of boundary spanning faculty, researchers might explore which roles are associated with career stages among faculty, and what types of support structure and educational development are appropriate for each stage. This insight could inform possible career trajectories of boundary spanners in higher education settings. Notably, this area of inquiry could inform a developmental, tiered identification of competencies that could be used to identify high potential candidates for boundary spanning roles, identify strengths and areas of growth for existing boundary spanners, and help to identify targeted learning and professional development interventions based upon current and aspirational boundary spanning roles and competency proficiency. Much attention has been given to the integration of community engagement principles at the graduate level (see O'Meara, 2008a). Eatman (2012) emphasizes the values of tools to support career planning pathways and notes the importance of mentoring, which echoes our participants' recommendations. As such, we encourage scholars to include graduate-level academic preparation in such exploration of career trajectories and requisite educational development.

Finally, scholars are encouraged to consider contextual variance including institutional types, disciplines and interdisciplinary fields, among others. We posit all community-engaged faculty are inherently boundary spanners by nature of their work, yet not all boundary spanning is community-engaged. Specific values differentiate community engagement from other types of university-community partnerships, so scholars must carefully consider the aims and objectives of their inquiry to ensure this important nuance is not lost. Related to contextual variance, the very nature of boundary spanning adds layers of complexity. Clifford 
and Petrescu (2012) suggest, "Working across disciplines and across the silos of academic departments and colleges is a hazardous business" (p. 85). Likewise, additional care should be given to work that spans university and community environments. While we do not consider the inherent risks of boundary spanning hazardous, per se, we agree that enhanced awareness and intentionality are essential mindsets for pursuing this important work.

\section{Conclusion}

Boundary spanning in higher education community engagement involves transmitting and translating knowledge between community and university partners and having the skills and knowledge necessary to navigate complex relationships as potential conflicts arise. Current literature on boundary spanning in community engagement provides a framework for the boundary spanning roles typically found on university campuses; however, there is limited research expounding upon the original Boundary Spanning Model. Additionally, shifting roles and responsibilities related to HECE and the Boundary Spanning Model, including faculty position types, hybrid faculty-administrative positions, and the emergence of the CEP, warrant a review of the model given our new context. Furthermore, existing scholarship inadequately leverages the concept's full potential in advancing community engagement in higher education.

This study synthesizes a growing body of literature on boundary spanners in higher education with emerging literature on professional competencies and educational development among faculty. It provides a preliminary foundation for further inquiry into the Boundary Spanning Model and associated competencies that support faculty members pursuing communityengaged teaching and research. Finally, this exploratory study contributes to a foundation from which a more robust inquiry into how we intentionally cultivate boundary spanning faculty and support their professional growth and development and the influence of these activities on the institutionalization of HECE. These insights contribute to the engaged university's core components and global efforts to institutionalize community engagement within higher education while promoting continued research in this promising area of scholarship on engagement related to higher education and academic leadership.

\section{About the Authors}

Jennifer W. Purcell (corresponding author) is an Associate Professor of Political Science in the School of Government and International Affairs at Kennesaw State University.

Email: jpurce10@kennesaw.edu

Andrew J. Pearl is the Director of Community Engagement Research and Publications at the University of Alabama. 
Trina L. Van Schyndel is a Doctoral Candidate in Higher, Adult, and Lifelong Education at Michigan State University.

\section{References}

Adams, K. R. (2014). The exploration of community boundary spanners in university-community partnerships. Journal of Higher Education Outreach and Engagement, 18(3), 113-118.

Aldrich, H., \& Herker, D. (1977). Boundary spanning roles and organization structure. Academy of Management Review, 2(2), 217-230.

Armitage, T., \& Levac, L. (2015). Learning the development of community-engaged scholars through course-based learning: A student perspective. Engaged Scholar Journal: Community-Engaged Research, Teaching, and Learning, 1(1).

Austin A. E., McDaniels M. (2006). Preparing the professoriate of the future: Graduate student socialization for faculty roles. In J. C. Smart (Ed.), Higher education: Handbook of theory and research, 21. Springer. https://doi.org/10.1007/1-4020-4512-3_8

Beere, C. A., Votruba, J. C., \& Wells, G. W. (2011). Becoming an engaged campus: A practical guide for institutionalizing public engagement. John Wiley \& Sons.

Berkey, B., Meixner, C., Green, P. M., \& Eddins, E. A. (Eds.). (2018). Reconceptualizing Faculty Development in Service-Learning/Community Engagement. Stylus.

Blanchard, L. W., Hanssmann, C., Strauss, R. P., Belliard, J. C., Krichbaum, K., Waters, E., \& Seifer, S. D. (2009). Models for faculty development: What does it take to be a community-engaged scholar? Metropolitan Universities, 20(2), 47-65.

Bloomgarden, A., \& O’Meara, K. (2007). Faculty role integration and community engagement: Harmony or cacophony? Michigan Journal of Community Service Learning, 13(2), 5-18.

Bringle, R. B., Clayton, P. H., \& Price, M. F. (2009). Partnerships in service-learning and civic engagement. Partnerships: A Journal of Service Learning \& Civic Engagement, 1(1), 1-20.

Bruce, J. (2013). Service learning as a pedagogy of disruption. Journal of Developmental Education and Global Learning, 5(1), 33-47.

Buller, J. L. (2014). Change Leadership in Higher Education: A Practical Guide to Academic Transformation. Wiley.

Butin, D. (2015). Dreaming of justice: Critical service-learning and the need to wake up. 54, 5-10. Education and Global Learning, 5(1), 33-47.

Clifford, D., \& Petrescu, C. (2012). The keys to university-community engagement sustainability. Nonprofit Management and Leadership, 23(1), 77-91.

College \& University Engagement Initiative. (n.d.). Community Engagement: Defining Community Engagement. Retrieved from https://www.brown.edu/swearer/carnegie/about

Doberneck, D. M., Bargerstock, B. A., McNall, M., Van Egeren, L., \& Zientek, R. (2017). Community engagement competencies for graduate and professional students: Michigan State University's approach to professional development. Michigan Journal of Community Service Learning, 24(1), 122-142. 
Dostilio, L. D. (Ed.). (2017). The community engagement professional in higher education: A competency model for an emerging field. Stylus.

Eatman, T. K. (2012). The arc of the academic career bends toward publicly engaged scholarship. In A. Gilvin, G. M. Roberts, \& C. Martin (Eds.), Collaborative futures: Critical reflections on publicly active graduate education (pp. 25-48). The Graduate School Press.

Fitzgerald, H. E., Bruns, K., Sonka, S. T., Furco, A., \& Swanson, L. (2012). The centrality of engagement in higher education. Journal of Higher Education Outreach and Engagement, 16(3), 7-28.

Friedman, R. A., \& Podolny, J. (1992). Differentiation of boundary spanning roles: Labor negotiations and implications for role conflict. Administrative Science Quarterly, 37(1), 28-47. https://doi.org/10.2307/2393532

Glaser, B. G., \& Strauss, A. L. (1967). The discovery of grounded theory: Strategies for qualitative research. Aldine.

Gmelch, W. H., \& Buller, J. L. (2015). Building academic leadership capacity: A guide to best practices. John Wiley \& Sons.

Gavazzi, S. M., \& Gee, E. G. (2018). Land-grant universities for the future: Higher education for the public good. JHU Press.

Jacoby, B. (2014). Service-learning essentials: Questions, answers, and lessons learned. Jossey-Bass.

Kezar, A., \& Lester, J. (2011). Enhancing campus capacity for leadership: An examination of grassroots leaders in higher education. Stanford University Press.

Kline, C., Asadian, W., Godolphin, W., Graham, S., Hewitt, C., \& Towle, A. (2018). From "Academic Projectitis" to partnership: Community perspectives for authentic community engagement in health professional education. Engaged Scholar Journal, 4(1), 79-96.

McReynolds, M., \& Shields, E. (2015). Diving deep in community engagement: A model for professional development. Iowa Campus Compact.

Merriam, S. B. (1998). Qualitative research and case study applications in education. Jossey-Bass.

Merriam, S. B. (2009). Qualitative research: A guide to design and implementation. Jossey-Bass.

Morrison, E., \& Wagner, W. (2017). A community-engaged faculty typology: A self-referent approach to understanding faculty perspectives. Michigan Journal of Community Service Learning, 23(2), 117-130.

Mull, C. (2016). A dissertation of boundary spanning actors within community engagement. Journal of Higher Education Outreach and Engagement, 20(2), 157-162.

O’Meara, K. (1997). Rewarding faculty professional service. New England Resource Center for Higher Education Publications, 17.

O'Meara, K. (2002). Uncovering the values in faculty evaluation of service as scholarship. Journal of Higher Education, 26(1), 57-80.

O’Meara, K. (2008a). Graduate education and community engagement. New Directions for Teaching and Learning, 113, 27-42.

O’Meara, K. (2008b). Motivation for public scholarship and engagement: Listening to exemplars. Journal of Higher Education Outreach and Engagement, 12(1), 7-29.

O’Meara, K. (2011). Faculty civic engagement: New training, assumptions, and markets needed for the engaged American scholar. In J. Saltmarsh \& M. Hartley (Eds.), "To serve a larger purpose": Engagement for democracy and the transformation of higher education (pp. 177-198). Temple University Press.

Engaged Scholar Journal: Community-Engaged Research, Teaching, and Learning 
O'Meara, K., \& Jaeger, A. J. (2006). Preparing future faculty for community engagement: Barriers, facilitators, models, and recommendations. Journal of Higher Education Outreach and Engagement, 11(4), 3-27.

Percy, S. L., Zimpher, N. L., \& Brukardt, M. J. (Eds.). (2006). Creating a new kind of university: Institutionalizing community-university engagement. Anker Publishing.

Post, M. A., Ward, E., Longo, N.V., \& Saltmarsh, J. (Eds.). (2016). Publicly engaged scholars: Nextgeneration engagement and the future of higher education. Stylus.

Ruben, B. D., De Lisi, R., \& Gigliotti, R. A. (2018). Academic leadership development programs: Conceptual foundations, structural and pedagogical components, and operational considerations. Journal of Leadership Education, 17(3). https://doi.org/10.12806/V17/I3/A5

Ruona, W. E. (2005). Analyzing qualitative data. In R. A. Swanson \& E. F. Holdton III (Eds.), Research in organizations: Foundations and methods of inquiry (pp. 233-263). Berrett-Koehler Publishers.

Saltmarsh, J., \& Hartley, M. (Eds.). (2011). "To serve a larger purpose”: Engagement for democracy and the transformation of higher education. Temple University Press.

Sandmann, L. R. (2009). Placing scholarly engagement "on the desk." Research University Engaged Scholarship Toolkit. Campus Compact.

Sandmann, L. R., \& Jones, D. O. (Eds.). (2019). Building the field of higher education engagement: Foundational ideas and future directions. Stylus.

Sandmann, L. R., Jordan, J. W., Mull, C. D., \& Valentine, T. (2014). Measuring boundary spanning behaviors in community engagement. Journal of Higher Education Outreach and Engagement, 18(3), 83-96.

Sandmann, L. R., \& Weerts, D. J. (2008). Reshaping institutional boundaries to accommodate an engagement agenda. Innovative Higher Education, 33(3), 181-196.

Shaffer, T. J., \& Longo, N. V. (Eds.). (2019). Creating space for democracy: A primer on dialogue and deliberation in higher education. Stylus.

Suvedi, M., \& Kaplowitz, M. (2016). What every extension worker should know: Core competency handbook. Michigan State University.

Tushman, M. L., \& Scanlan, T. J. (1981). Boundary spanning individuals: Their role in information transfer and their antecedents. Academy of Management Journal, 24(2), 289-305.

Van Meerkerk, I., \& Edelenbos, J. (2018). Boundary spanners in public management and governance: An interdisciplinary assessment. Edward Elgar.

Van Schyndel, T., Pearl, A. J., \& Purcell, J. W. (2019). Extending our conceptualization of boundaryspanning leadership for community engagement. Journal of Higher Education Outreach and Engagement, 23(2) 63-78.

Weerts, D. J., \& Sandmann, L. R. (2010). Community engagement and boundary spanning roles at research universities. The Journal of Higher Education, 81(6), 702-727.

Welch, M. (2016). Engaging higher education: Purpose, platforms, and programs for community engagement. Stylus.

Welch, M., \& Plaxton-Moore, S. (2017). Faculty development for advancing community engagement in higher education: Current trends and future directions. Journal of Higher Education Outreach and Engagement, 21(2), 131-165.

Welch, M., \& Plaxton-Moore, S. (Eds.). (2019). The craft of community-engaged teaching and learning. Stylus. 
Welch, M., \& Saltmarsh, J. (2013). Current practice and infrastructure for campus center of community engagement. Journal of Higher Education Outreach and Engagement, 17(4), 2555.

Whitchurch, C. (2013). Reconstructing identities in higher education: The rise of "third space" professionals. Routledge.

Whitchurch, C. (2015). The rise of third space professionals: Paradoxes and dilemmas. In U. Teichler \& W.K. Cummings (Eds.), Forming, recruiting and managing the academic profession (pp. 7999). Springer.

Williams, P. (2012). Collaboration in public policy and practice: Perspectives on boundary spanners. The Policy Press. 